\title{
Safety Assessment Method for the Crane Structure Based on the Unacertained Measuring Theory
}

\author{
Yang Rui-gang, Lu Yi, Wang Lei and Xu Ge-ning \\ School of Mechanical Engineering, Taiyuan \\ University of Science \&Technology, Taiyuan 030024, China
}

\begin{abstract}
The paper is engaged in a study of the crane structure safety assessment method based on the unascertained measuring theory. With the rapid economic development of modern society, more and more widely use of various cranes are found in the construction and transportation areas, particularly, in the construction area. With the increase of the national infrastructure investment, much greater varieties of crane demands have been brought about to the crane manufacturers. However, higher and higher standards have been established to the safety operations of crane installations and workers' operation skills so as to protect people and material properties from any kind of unexpected accidents in addition to the social stability. It is just from this increasing safety need that we have worked out a safety evaluation model by using the unascertained mathematical theory, which is featured as being simple, practical and reliable. The safety evaluation model we proposed for the overhead crane can be divided into four stages, by using the assessment indexes as unascertained information and the confidence level. Taking 5 overhead cranes as examples, by identifying a single indicator matrix and unascertained measure weights, we have formulated a multi-attribute integrated measurement matrix system with the sample being identified and sorted out. The results of our assessment practice prove to be in nice conformity with the results of the software analysis results. The model initiated by us can not only help to evaluate a single crane security, but also the cranes with roughly equal security situations. Case studies also show that the use of unascertained measure model is reasonable in theory and credible in results. It not only includes ordering of information uncertainty but also the evaluation of the space, so that the evaluation result can be made rational, sophisticated and practical.
\end{abstract}

Keywords: Safety engineering, Crane safety assessment, Unascertained measure, Safety assessment model

\section{Introduction}

Crane is widely used in metallurgy, electricity, logistics, machinery manufacturing, construction and other industries, plays an integral role in raising labor productivity and mechanization of production processes. With the rapid development of economy, the use of the crane is more and more widely. Especially with the investment in national infrastructure is growing, increasingly high demand for cranes, the lifting weight tends to heavy load, dead weight tends to light, space tends to large-scale, time tends to high speed and operation tends to frequent. With the continuous development of crane, the demand of economy and safety of engineering equipment becomes higher. The safe operation of crane 
related to people's life and property safety, and social stability, it is an important part of the national public security. According to incomplete statistics, in recent years the global crane accidents rose rapidly, the number of deaths increased year by year [1-3]. Therefore, a comprehensive evaluation of the scientific method is required to assess the safety of crane.

Currently, both qualitative methods and quantitative methods can be used for safety assessment, but most only for safety evaluation of construction projects. There are a lot of unascertained factors in the pre-evaluation, these evaluation method is difficult to obtain reliable evaluation results. The unascertained mathematics is mainly used to study uncertain information, by establishing unascertained measure model, the confidence level recognition criteria and analyzing indicators factors to determine the index factors of reliability. It is simplicity, relevance, practicality and reliability. Compared with fuzzy comprehensive evaluation, gray clustering analysis, matter-element analysis, BP artificial neural network and so on, the unascertained measure evaluation model is rigorous, its evaluation result is reasonable, fine and high resolution, more suitable for safety pre-evaluation. If the evidence is not sufficient to hold true relationship of things between the number or the real state of things, resulting in uncertainty on the subjective understanding of the minds of decision-makers, known as unascertained. It is proposed in the study of construction engineering theory by Professor Wang Guangyuan Harbin Institute of Technology, the Chinese Academy of Engineering. All systems with behavioral factors are unascertained. There are problems in safety evaluation, how to quantitatively describe the things which are in unascertained state or having the nature of unascertained. Currently, the method is mainly used for mine ventilation system safety assessment [4], lake water environment assessment [5], urban environmental quality evaluation [6], for crane safety assessment has not been reported. The paper talk about the crane safety assessment method of unascertained measuring theory.

\section{Unascertained Measure Evaluation Model}

Assume that, object space $U=\left\{x_{1}, x_{2}, \cdots, x_{n}\right\}$, index space $I=\left\{I_{1}, I_{2}, \cdots, I_{m}\right\}$, evaluate space $C=\left\{c_{1}, c_{2}, \cdots, c_{p}\right\}$.Measured values on indicators of object $x_{i}$ can be expressed as an index of dimensional vector $\boldsymbol{x}_{i}=\left(x_{i 1}, x_{i 2}, \cdots, x_{i m}\right)(i=1,2, \cdots, n)$.If the evaluation level $c_{k}$ is "strong" than $c_{k+1}$, recorded as $c_{k}>c_{k+1}$, if $c_{1}>c_{2}>c_{3}>\cdots>c_{p}$, says $\left\{c_{1}, c_{2}, \cdots, c_{p}\right\}$ is ordered.

\subsection{Single Index Unascertained Measure}

If the degree of measured values $x_{i j}$ belong to class $c_{k}$ show in $\mu_{i j k}=\mu\left(x_{i j} \in c_{k}\right)$, and $\mu$ meet

$$
\begin{gathered}
0 \leq \mu\left(x_{i} \in c_{k}\right) \leq 1 \quad(i=1,2, \cdots, n ; \quad j=1,2, \cdots, m ; \quad k=1,2, \cdots, p) \\
\mu\left(x_{i} \in U\right)=1 \quad(i=1,2, \cdots, n ; \quad j=1,2, \cdots, m) \\
\mu\left|x_{i} \in \begin{array}{l}
k \\
U c_{l}
\end{array}\right|=\sum_{l=1}^{k} \mu\left(x_{i} \in c_{k}\right)
\end{gathered}
$$

When $\mu$ meet the formula (1), (2), (3),it is called unascertained measure.The vector $\left(\mu_{i j 1}, \mu_{i j 2}, \cdots, \mu_{i j p}\right)$ as single indicator unascertained vector for $x_{i}$. The matrix

$$
\left(\mu_{i j k}\right)_{m \times p}=\left(\begin{array}{llll}
\mu_{i 11} & \mu_{i 12} & \cdots & \mu_{i 1 p} \\
\mu_{i 12} & \mu_{i 22} & \cdots & \mu_{i 2 p} \\
\cdots & \cdots & \cdots & \cdots \\
\mu_{i m 1} & \mu_{i m 2} & \cdots & \mu_{i m p}
\end{array}\right)(i=1,2, \cdots, n)
$$


is single index unascertained measure evaluation matrix for sample.

\subsection{Index Distinguish Weight}

Assume that, the vector $\left(\mu_{i j 1}, \mu_{i j 2}, \cdots, \mu_{i j p}\right)$ is single index unascertained measure vector for $x_{i}$. Let

$$
\begin{gathered}
v_{j}^{(i)}=1+\frac{1}{\lg p} \sum_{k=1}^{p} \mu_{i j k} \lg \mu_{i j k} \\
w_{j}^{(i)}=\frac{v_{j}^{(i)}}{\sum_{j=1}^{m} v_{j}^{(i)}}
\end{gathered}
$$

The weight $w_{j}^{(i)}$ of the $j$-th index of $x_{i}$ is got by the formula (5) and (6),obviously $0 \leq w_{j}^{(i)} \leq 1$, and $\sum_{j=1}^{m} w_{j}^{(i)}=1$. The weight obtained by the method reflects the importance of the index for classification of $x_{i}$, the greater value of the weight $w_{j}^{(i)}$, the greater role of the index $j$ when classified evaluation index $i$ in a certain category.

\subsection{Multi-index Comprehensive Measure Evaluation Matrix}

Let $\mu_{i k}=\mu\left(x_{i} \in c_{k}\right)$, it means that the object $x_{i}$ belongs to the $\mathrm{i}$-th degree of evaluation level $c_{k}$, then

$$
\mu_{i k}=\sum_{j=1}^{m} w_{j} \mu_{i j k} \quad(i=1,2, \cdots, n ; k=1,2, \cdots, p)
$$

easy to verify that $\mu_{i k}$ meet unascertained measurement conditions, so $\mu_{i k}$ was unascertained measure.

Assume $\left(\mu_{i 1}, \mu_{i 2}, \cdots, \mu_{i p}\right)$ is comprehensive measurement evaluation vector of objects $x_{i}$,then multi-index comprehensive measure evaluation matrix is $\mu_{i k}=\left(\begin{array}{llll}\mu_{11} & \mu_{12} & \cdots & \mu_{1 p} \\ \mu_{21} & \mu_{22} & \cdots & \mu_{2 p} \\ \cdots & \cdots & \cdots & \cdots \\ \mu_{n 1} & \mu_{n 2} & \cdots & \mu_{n p}\end{array}\right)$.

\subsection{Rating Criteria Identify}

Using confidence level recognition criterion, let confidence level is $\lambda,(\lambda>0.5$ taking $\lambda$ $=0.6$ or 0.7$)$, if $c_{1}>c_{2}>\cdots>c_{p}$

$$
k_{0}=\min \left[k: \sum \mu_{i l} \geq \lambda, k=1,2, \cdots, p\right]
$$

then $x_{i}$ belong to the $k_{0}$-th evaluation class $c_{k_{0}}$.

If $c_{1}>c_{2}>\cdots>c_{p}$, and the value of evaluation level $c_{l}$ of the $l$-th is $n_{l}$, then $n_{l}>n_{l+1}$, let

$$
q_{x_{i}}=\sum_{l=1}^{p} n_{l} \mu_{i l}
$$

then $q_{x_{i}} \mathrm{x}$ is the total score of the object $x_{i}$, the objects $x_{i}$ are ranked by the size of the $q_{x_{i}} \cdot$

\section{Universal Bridge Crane Safety Evaluation System}

Bridge crane is located at the top of the workshop, warehouse and yard, it is lifting 
equipment for material lifting. Because both of its ends are situated on tall concrete pillars or metal stents, shaped like a bridge, so called "crane" or "carriageway." Bridge crane generally consists of three parts, lifting trolley, bridge traveling mechanism and bridge metal structures. The lifting trolley was composed of lifting mechanism, trolley traveling mechanism and trolley frame. Lifting mechanism includes a motor, brake, reducer, drum and pulley block. Reducer driven by a motor to rotate the reel, make rope from around the reel or roll down to lift a heavy weight. Trolley frame is used for bracing and mounting lifting mechanism and trolley traveling mechanism and so on, they are usually welded structure. Drive mode of crane traveling mechanism can be divided into two categories: one for centralized driving, which uses an electric motor to drive the long propeller shaft drive wheels on both sides of the initiative; another for respective driving that is on both sides of the active wheel with an electric motor driven. Medium and small overhead crane are more using a combination of brakes, speed reducer and motor as the "triple play" drive mode, large lifting capacity of ordinary bridge crane for ease of installation and adjustment, often using universal joint drive. Bridge's metal structure from the main beam and side beams, divided into single-beam bridge and dual-beam bridge. Dual-beam bridge composed of two main beams and end beams, the main beam and end beam rigid connection, both ends of the end beam equipped with wheels for supporting the bridge runs on an elevated. Main beam welded rail for lifting trolley. There are Many types of bridge girder structure, such as box-shaped structure, four truss structure and fasting truss structure. Main beam is composed of the upper and lower flange plates and web plate on both sides, trolley rails arranged on the center line of the flange plate, simple structure, easy to manufacture, suitable for mass production, but large dead weight. Based on the above analysis, universal overhead crane safety evaluation are shown in Table 1, a total of 16.According to the working characteristics of the bridge crane, the security situation is divided into four, shown in Table 2.

\section{Table 1. Safety Evaluation Index for General Overhead Traveling Crane}

\begin{tabular}{|c|c|c|}
\hline NO. & Evaluation & Evaluation content \\
\hline$I_{1}$ & $\begin{array}{l}\text { Bridge structure } \\
\text { connecting }\end{array}$ & Weld defects, high strength bolt preload, etc. \\
\hline$I_{2}$ & $\begin{array}{l}\text { Deformation of Bridge } \\
\text { cracks }\end{array}$ & $\begin{array}{l}\text { The main beam's under deflection, plastic deformation, } \\
\text { cracks, rigidity, etc. }\end{array}$ \\
\hline$I_{3}$ & $\begin{array}{l}\text { Rope of hoisting } \\
\text { mechanism }\end{array}$ & $\begin{array}{l}\text { Selection, deformation, broken wires, broken rope, } \\
\text { corrosion, thermal damage, etc. }\end{array}$ \\
\hline$I_{4}$ & $\begin{array}{l}\text { pulley block of } \\
\text { Hoisting mechanism }\end{array}$ & $\begin{array}{l}\text { Pulley, wheel rim and groove wear, rope off the tank and } \\
\text { jamming, whether pulley rotation is flexible }\end{array}$ \\
\hline$I_{5}$ & $\begin{array}{l}\text { Hook of Hoisting } \\
\text { mechanism }\end{array}$ & $\begin{array}{l}\text { Selection, Surface and tail hook thread cracks, dangerous } \\
\text { section of wear, neck plastic deformation }\end{array}$ \\
\hline$I_{6}$ & $\begin{array}{l}\text { Brakes of Hoisting } \\
\text { mechanism }\end{array}$ & $\begin{array}{l}\text { Brake pads, worn brake wheels, brake operation, the brakes } \\
\text { hold of the situation, etc. }\end{array}$ \\
\hline$I_{7}$ & $\begin{array}{l}\text { Reel of Hoisting } \\
\text { mechanism }\end{array}$ & Crack deformation, rope end is fixed, secure laps, etc. \\
\hline$I_{8}$ & $\begin{array}{l}\text { Safety devices of } \\
\text { Hoisting mechanism }\end{array}$ & $\begin{array}{l}\text { Height limit brakes, crane limiter, anti-decoupling device, } \\
\text { short circuit protection, loss protection, etc. }\end{array}$ \\
\hline$I_{9}$ & $\begin{array}{l}\text { Appliances of Hoisting } \\
\text { mechanism }\end{array}$ & Power cables, controllers, contactors, motor, reducer, etc. \\
\hline$I_{10}$ & Orbit of run institutions & $\begin{array}{l}\text { Rail wear, rail connection, rail joint gap, gauge deviation, } \\
\text { etc. }\end{array}$ \\
\hline$I_{11}$ & Reel of run institutions & Wheel wear, rim wear, track deviation, etc. \\
\hline$I_{12}$ & $\begin{array}{l}\text { Safety devices of run } \\
\text { institutions }\end{array}$ & $\begin{array}{l}\text { Stroke limiter, buffers, sweeping rail plate, chain protection, } \\
\text { voltage protection, overcurrent protection, etc. }\end{array}$ \\
\hline$I_{13}$ & $\begin{array}{l}\text { Appliances of run } \\
\text { institutions }\end{array}$ & $\begin{array}{l}\text { Power cables, controllers, contactors, relays, motors, } \\
\text { reducers, etc. }\end{array}$ \\
\hline$I_{14}$ & Security Management & Safety rules and regulations, safety Procedures, security \\
\hline
\end{tabular}




\begin{tabular}{|c|c|c|}
\hline$I_{15}$ & $\begin{array}{l}\text { The quality of } \\
\text { personnel }\end{array}$ & $\begin{array}{l}\text { education, security, procuratorial, etc. } \\
\text { Driver's license of special equipment, personnel training, } \\
\text { physical and mental qualities }\end{array}$ \\
\hline$I_{16}$ & Safety and security & $\begin{array}{l}\text { Life insurance, security facilities, security investments, } \\
\text { security and culture, etc. }\end{array}$ \\
\hline
\end{tabular}

Table 2. Safety Ratings for General Overhead Traveling Crane

\begin{tabular}{|c|c|c|}
\hline Class NO. & Rating & Rating evaluate the degree \\
\hline$c_{1}$ & A & The machine is in a safe operating state \\
\hline$c_{2}$ & B & $\begin{array}{l}\text { Most of the aircraft in line with safety indicators, there is a small } \\
\text { number of indicators of non-compliance }\end{array}$ \\
\hline$c_{3}$ & $\mathrm{C}$ & $\begin{array}{l}\text { Most aircraft safety indicators are not fully consistent with a greater } \\
\text { impact on aircraft }\end{array}$ \\
\hline$c_{4}$ & $\mathrm{D}$ & $\begin{array}{l}\text { There is a big security risk, most do not meet the requirements of } \\
\text { safety indicators }\end{array}$ \\
\hline
\end{tabular}

\section{General Bridge Crane Unascertained Measure Safety Assessment}

There are five bridge cranes in this paper, called bridge crane $1 \sim 5$. Bridge crane 1 using literature [7] provided an example to calculate, the sample specific circumstances of which shown in Table 3.

\section{Table 3. Samples for General Overhead Traveling Crane}

\begin{tabular}{ll}
\hline Cranes name & \multicolumn{1}{c}{ Security situation } \\
\hline Bridge crane 1 & An enterprise bridge crane, see specific literature [7] \\
Bridge crane 2 & A corporate assembly shop crane, the age of 15 a \\
Bridge crane 3 & A corporate assembly shop crane, the use of time is 6 a \\
Bridge crane 4 & A corporate assembly shop crane, the use of time is 5 a \\
Bridge crane 5 & A corporate assembly shop crane, the use of time is 4.5 a \\
\hline
\end{tabular}

\subsection{Single Index Unascertained Measure Matrix}

According to the evaluation index of general overhead crane (Table 1 and 2) to evaluate the actual level of the security situation for bridge crane 1 by ten evaluators. Such as Indicator 1 "bridge structure connection", according to "weld defects, high strength bolt preload" to rate. If the 10 experts have two play "A", five play "B", three play " $\mathrm{C}$ ", no one play the " $\mathrm{D}$ ", then the first row of the matrix is $\left(\begin{array}{lll}0.2 & 0.5 & 0.3\end{array}\right.$ $0)$.Similarly, the evaluated results of other rows same can be obtained. With the data of bridge crane 1, according to the data provided by the literature [7] to establish the following matrix. 
International Journal of $u-$ and e- Service, Science and Technology Vol.8, No. 8 (2015)

$$
\left(\mu_{1 j k}\right)_{16 \times 4}=\left(\begin{array}{llll}
0.2 & 0.5 & 0.3 & 0 \\
0.5 & 0.3 & 0.1 & 0.1 \\
0 & 0.2 & 0.4 & 0.4 \\
0.3 & 0.4 & 0.3 & 0 \\
0.1 & 0.5 & 0.4 & 0 \\
0.4 & 0.5 & 0.1 & 0 \\
0.6 & 0.2 & 0.1 & 0.1 \\
0.2 & 0.4 & 0.4 & 0 \\
0 & 0.2 & 0.5 & 0.3 \\
0.2 & 0.4 & 0.2 & 0.2 \\
0 & 0.2 & 0.7 & 0.1 \\
0.1 & 0.1 & 0.8 & 0 \\
0.3 & 0.5 & 0.2 & 0 \\
0.3 & 0.4 & 0.2 & 0.1 \\
0 & 0.1 & 0.6 & 0.3 \\
0.2 & 0.3 & 0.5 & 0
\end{array}\right)
$$

Similarly, the remaining four samples of single index measurement matrix can be drawn, $\left(\mu_{i j k}\right)_{16 \times 4}(i=1,2, \cdots, 5)$.

$\left(\mu_{2 j k}\right)_{16 \times 4}=\left(\begin{array}{llll}0.1 & 0.2 & 0.4 & 0.3 \\ 0.2 & 0.2 & 0.3 & 0.3 \\ 0 & 0.2 & 0.3 & 0.5 \\ 0.1 & 0.3 & 0.3 & 0.3 \\ 0 & 0.3 & 0.4 & 0.3 \\ 0.2 & 0.3 & 0.2 & 0.3 \\ 0.2 & 0.2 & 0.1 & 0.5 \\ 0.2 & 0.3 & 0.3 & 0.2 \\ 0 & 0.2 & 0.4 & 0.4 \\ 0.1 & 0.4 & 0.2 & 0.3 \\ 0 & 0.2 & 0.4 & 0.4 \\ 0.1 & 0.2 & 0.4 & 0.3 \\ 0.2 & 0.4 & 0.2 & 0.2 \\ 0.2 & 0.3 & 0.2 & 0.3 \\ 0 & 0.1 & 0.4 & 0.5 \\ 0.1 & 0.3 & 0.2 & 0.4\end{array}\right),\left(\mu_{3 j k}\right)_{16 \times 4}=\left(\begin{array}{llll}0.2 & 0.3 & 0.3 & 0.2 \\ 0.3 & 0.2 & 0.3 & 0.2 \\ 0.1 & 0.2 & 0.3 & 0.4 \\ 0.2 & 0.3 & 0.3 & 0.2 \\ 0.2 & 0.3 & 0.2 & 0.3 \\ 0.1 & 0.4 & 0.3 & 0.2 \\ 0.3 & 0.2 & 0.3 & 0.2 \\ 0.2 & 0.3 & 0.3 & 0.2 \\ 0 & 0.4 & 0.2 & 0.4 \\ 0.2 & 0.3 & 0.3 & 0.2 \\ 0 & 0.3 & 0.3 & 0.4 \\ 0.2 & 0.2 & 0.3 & 0.3 \\ 0.2 & 0.3 & 0.3 & 0.2 \\ 0.2 & 0.2 & 0.4 & 0.2 \\ 0.2 & 0.2 & 0.4 & 0.2 \\ 0.1 & 0.4 & 0.2 & 0.3\end{array}\right)$




$$
\left(\mu_{4 j k}\right)_{16 \times 4}=\left(\begin{array}{cccc}
0.2 & 0.2 & 0.4 & 0.2 \\
0.2 & 0.1 & 0.3 & 0.4 \\
0.1 & 0.3 & 0.3 & 0.3 \\
0.2 & 0.4 & 0.2 & 0.2 \\
0.1 & 0.5 & 0.3 & 0.1 \\
0.5 & 0.3 & 0.2 & 0 \\
0.3 & 0.2 & 0.2 & 0.3 \\
0.4 & 0.2 & 0.3 & 0.1 \\
0.3 & 0.2 & 0.3 & 0.2 \\
0.3 & 0.4 & 0.2 & 0.1 \\
0.2 & 0.3 & 0.3 & 0.2 \\
0.2 & 0.3 & 0.3 & 0.3 \\
0.4 & 0.3 & 0.2 & 0.1 \\
0.4 & 0.3 & 0.2 & 0.1 \\
0.3 & 0.3 & 0.2 & 0.2 \\
0.5 & 0 & 0.3 & 0.2
\end{array}\right), \quad\left(\mu_{5 j k}\right)_{16 \times 4}=\left(\begin{array}{llll}
0.2 & 0.3 & 0.3 & 0.2 \\
0.5 & 0.2 & 0.3 & 0 \\
0.2 & 0.3 & 0.2 & 0.3 \\
0.3 & 0.4 & 0.2 & 0.1 \\
0.2 & 0.4 & 0.3 & 0.1 \\
0.4 & 0.3 & 0.2 & 0.1 \\
0.3 & 0.3 & 0.2 & 0.2 \\
0.3 & 0.2 & 0.4 & 0.1 \\
0.4 & 0.2 & 0.3 & 0.1 \\
0.3 & 0.5 & 0.2 & 0 \\
0.3 & 0.3 & 0.2 & 0.2 \\
0.3 & 0.3 & 0.2 & 0.2 \\
0.4 & 0.3 & 0.2 & 0.1 \\
0.4 & 0.3 & 0.2 & 0.1 \\
0.3 & 0.3 & 0.2 & 0.2 \\
0.5 & 0 & 0.3 & 0.2
\end{array}\right)
$$

\subsection{Determine the Index Weight Of General Bridge Crane 1}

By the formula (5) and (6) to get intermediate process variables and indicators weight vector of bridge crane 1 .That is

$$
\begin{gathered}
\boldsymbol{V}=\left(v_{1}, v_{2}, \cdots, v_{16}\right)^{\mathrm{T}}=(0.2580,0.1584,0.0985,0.6838,0.3140,0.3140,0.3149, \\
0.0985,0.2580,0.0985,0.1058,0.5393,0.2580,0.0767,0.3524,0.2580)^{\mathrm{T}} \\
\boldsymbol{W}=\left(w_{1}, w_{2}, \cdots, w_{16}\right)^{\mathrm{T}}=(0.0165,0.0378,0.0235,0.1631,0.0749,0.0749,0.0751, \\
0.0235,0.0615,0.0235,0.0252,0.1287,0.0615,0.0183,0.0841,0.0615)^{\mathrm{T}}
\end{gathered}
$$

\subsection{Determine Multi-index Comprehensive Measure Matrix}

According to equation (7) obtained multi-index comprehensive measure evaluation matrix from single index measure evaluation matrix and index weight vector.

$$
\left(\mu_{i k}\right)_{5 \times 4}=\left(\begin{array}{cccc}
0.304 & 0.312 & 0.290 & 0.092 \\
0.074 & 0.183 & 0.345 & 0.403 \\
0.407 & 0.298 & 0.180 & 0.115 \\
0.360 & 0.346 & 0.133 & 0.161 \\
0.398 & 0.338 & 0.217 & 0.047
\end{array}\right)
$$

\subsection{Sample Identification and Sort}

Evaluation samples can be identified and sorted according to the comprehensive measure matrix. In unascertained measure model, the value of the confidence level ${ }^{\lambda}$ has impact on the results of sample classification. Generally, in the case of higher reliability evaluation index data, the values of the confidence level $\lambda$ may be slightly larger. Let the confidence level $\lambda$ is 0.7 , can easily make the evaluation: for bridge crane 1 , the sum of the former three, $0.304+0.312+0.29 \geq 0.7$, therefore, the security level of bridge crane 1 is $\mathrm{C}$. Similarly, the security level of bridge crane 2 is D, bridge crane3, 4 and 5 are B. In practical applications, suitable value of the confidence level depending on the circumstances.

Take $n_{k}=4-k$, substituting into equation (9) and obtaining $q_{x_{i}}=\left(q_{x_{1}}, q_{x_{2}}, \cdots q_{x_{5}}\right)=$ $(2.824,2.163,093, .283,40) 1$.The greater the value of $q_{x_{i}}$, show that the higher the safety degree of the bridge crane; on the contrary, the lower. Therefore, by 
$q_{x_{5}}>q_{x_{4}}>q_{x_{3}}>q_{x_{1}}>q_{x_{2}}$ known that the order of samples' evaluation is $x_{5}>x_{4}>x_{3}>x_{1}>x_{2}$, the sort of safety evaluation sample is : bridge crane 5 , bridge crane 4 , bridge crane 3 , bridge crane 1 , bridge crane 2 .

The data of bridge crane 1 is provided by literature[7], the same results as literature [7], security level is C. Method presented in this paper can make order for bridge crane at the same level of security, and provide reference for technicians and inspectors.

The evaluation method of this paper and the literature [7] can draw the same conclusion that bridge crane 1 security level is " $\mathrm{C}$ ". But for the same security level of bridge crane, the security situation is not exactly the same. Fuzzy comprehensive evaluation method can only made safety evaluation method for one bridge crane, for the same level of security of bridge crane, its security status cannot be obtained by this method. For the sequence problem of many bridge crane safety, comparing the results of the analysis of two sortwares, "Bridge crane key component reliability analysis system software"(Grant number 2009SR00551), "Bridge crane structure residual fatigue life evaluation system software" (Grant number 2009SR00549). The results of the method are consistent with the software, because the space is limited, the specific analysis will be discussed in another article.

\section{Conclusions}

The paper establishes a unascertained measure evaluation model, the model derives from unascertained characteristics of crane, the evaluation properties considered as unascertained to evaluate the security situation of bridge crane. Take the confidence value of 0.7 , the security level of the bridge crane $1 \sim 5$ are obtained. In practical applications, determine the appropriate value of the confidence level depending on the circumstances. Case study shows that applying the unascertained measure model for crane safety evaluation is reasonable in theory, and the calculation result is credible.

The safety evaluation model of unascertained measuring space in the paper both consider the "orderly" of space and the "uncertainty information", tend to make the results more reasonable and fine. The Meaning of unascertained measure model is Clear, the calculation result is relatively simple.

\section{References}

[1] S. Hong, "J. Manufacuring License system in safety management of China's hoisting machinery", Technology \& Management for Construction Machinery, no. 12, (2005), pp. 22-24.

[2] "General Administration of Supervision, Inspection and Quarantine of the People's Republic of China", Special equipment safety situation of China in 2007, Beijing: General Administration of Supervision, Inspection and Quarantine of the People's Republic of China, (2008).

[3] "State Council Order No. 549.Regulations on safety supervision of special equipment",. Beijing: the State Council, (2003).

[4] L. Yunqing, "Mine ventilation system unascertained measure and application of safety assessment method", Mining Safety \& Environmental Protection, no. 2, (2006), pp. 81-85.

[5] L. Ruzhong, "Unascertained measurement evaluation on sustainable utilization of regional water resources", China Rural Water and Hydropower, no. 12, (2004), pp. 43-46.

[6] L. Kaidi, "The unascertained measurement evaluation on a city's environmental quality", System Engineering-Theory \& Practice, vol. 19, no. 12, (1999), pp. 52-58.

[7] X. Gening, "Safety assessment on the crane based on FAHP", Journal of safety and Environment, vol. 10, no. 4, (2010), pp. 196-200. 